\title{
Investigation of Potential Grounding Compound for Portable Applications
}

\author{
N.A.M. Hasni, R. Abd-Rahman, H. Ahmad, N.A.M. Jamail, M.S. Kamaruddin, S.S. Ridzwan \\ Faculty of Electrical and Electronic Engineering, Universiti Tun Hussein Onn Malaysia, Malaysia
}

\begin{tabular}{l}
\hline \hline Article Info \\
\hline Article history: \\
Received Jun 18, 2017 \\
Revised Sep 20, 2017 \\
Accepted Oct 15, 2017 \\
\hline
\end{tabular}

Keyword:

Bauxite

Grounding material

Kaolin

Lightning flashover

Portable grounding system

\begin{abstract}
This paper applies to the electrical engineering world by making earthing system portable in providing low and acceptable resistance path. The system is develop in a small scale portable earthing system against the massiveness of Earth and becomes leverage if soil at the place is not suitable for plant grounding system. Hence, this paper presents findings on the research of new grounding medium material that will be housed in a small scale enclosure which behaves like native earth related earthing system by using kaolin and bauxite. The data obtained from lightning flashover testing, morphological and chemical composition of material analysis indicated that bauxite is more useful for portable grounding system application much better than kaolin in term of zero reference point function. The portable earthing system can be apply to air aviation systems, railway systems and military sectors particularly for electronic equipment zero referencing.
\end{abstract}

Copyright $\odot 2017$ Institute of Advanced Engineering and Science. All rights reserved.

Corresponding Author:

N.A.M. Hasni,

Faculty of Electrical and Electronic Engineering,

Universiti Tun Hussein Onn Malaysia,

86400 Parit Raja, Batu Pahat, Johor, Malaysia.

Email: ge150098@siswa.uthm.edu.my

\section{INTRODUCTION}

In electrical system, electrical equipments are always equipped with grounding system. It provides a short path for the high amplitude current cause by lightning strike or fault in electrical system from the origin point to the earth. Grounding should stabilize the voltage potential and act as a zero potential reference point to ensure the safe operation of power system, electrical equipment and to human being [1]. A good grounding system is able to provide low resistance path. International Electrotechnical Commission (IEC) state maximum allowable resistance is $10 \mathrm{ohm}$.

Besides that, the good grounding is designed to keep people safety, protect structure of building and equipment from unintentional contact with energized electrical lines, electrical noise reduction and to establish a point of reference [2], [3]. Ground fault occurrence forces the value of step voltage, touch voltage must be keep below the permissible limits [4] and ground potential rise value also should be lower to avoid damaged to equipment.

Earth acts as a reservoir of charge and able to neutralize an electric current by balance the charge between the charge equipment and ground. The ground capable to transfer or receiving charges from charged equipment in order to neutralize that electrical equipment [5]. If suddenly fault is happen and the equipment becomes energized, electricity will conducted to earth by creating short circuit and immediately will trip the electric supply circuit breaker. Then, there will be no dangerous voltage existing as a shock risk to anyone [6].

Soil grounding mediums have different resistivity due to physical and chemical composition. In order to maintain lowest possible grounding resistance, researchers and engineers have attempted various approached to reduce the resistance by mean of conventional long vertical electrode attached with multiple 
rods and also soils treatment. As an option, this paper proposes the use of alternative grounding material to be used for portable grounding system. This approach will provides a temporary access grounding point which can be used or shift to anywhere for sensitive equipment [7] and becomes leverage if soil at the place is not suitable for plant grounding system.

Concept of portable grounding system is implemented from conventional grounding system. The different is, grounding rod of conventional grounding system is dig in mother earth while grounding rod of portable grounding system is dig in soil filled in container.

Resistance of ground electrode are at three locations as shown in Figure 1. First is resistance of the electrode itself and all conductors and leads connected to it. The resistance is generally very low as ground rod is made of from conductive and low resistance material such as steel or copper. Second is the contact resistance between the surrounding earth (soil) to the electrode. The resistance almost negligible as ground electrode is free of paint, grease and is in firm contact with the earth. Third is the resistance of the surrounding earth. The ground electrode driven into earth made up of concentric shells that have same thickness. Shells that close to ground electrode give greatest degree of resistance as it amounts of area is smallest. The next earth shell that larger in area offer less resistance. The electrode is radiates current in all directions [8].

This paper aims in analyzing the lightning flashover that strike the selected grounding material by looking to its physical and chemical aspect. The best material is determined, in perform well as native earth.

In this paper, material use as grounding rod is made from copper. Kaolin and bauxite is used as grounding medium that fill in portable grounding system. The volume of grounding medium is $19.5 \mathrm{~cm} \times 19.5 \mathrm{~cm} \times 11.5 \mathrm{~cm}$.

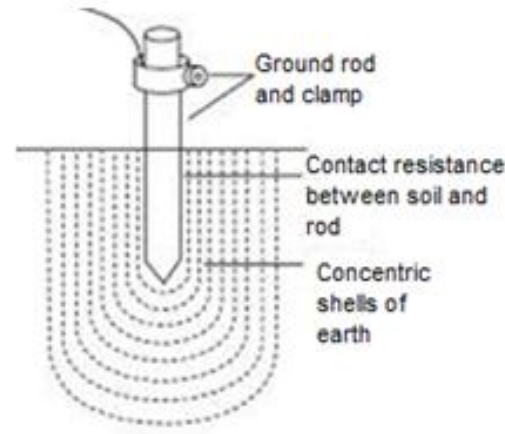

Figure 1. Components of earth resistance in an earth electrode [8]

\section{RESEARCH METHOD}

\subsection{Selection of Grounding Material}

In this research work, two materials which are kaolin and bauxite, have been shortlisted to be used as grounding material. In earth perspective, a medium act to allow electric charge to flow in forms of cation and anion from positive terminal to negative terminal. Material is select according to its resistivity. Kaolin which are in clay group are low in resistivity due to its ability to absorb $37 \%$ of water while the bauxite able to absorb $34.6 \%$. In chemical composition criteria, bauxite are compounds rich in metal elements. Meanwhile, kaolin made up of many non-metal elements in its compound which good as insulator.

\subsection{Sample Preparation for Testing}

Prior to laboratory testing, grounding samples are carefully prepared to control over its grain size and water content. Initially each sample of material is dried in an oven at $105^{\circ} \mathrm{C}$ for 48 hours according to the standard [9]. The sample is then crushed using crusher machine to change from solid state into fine powder material. The crusher machine with 6 ball bearing inside the crusher crush the material during it rolled. The fine powder produced are not uniform in size, the material need to be sieve to get uniform grain size and separate impurity element from the material, by using sieve and sieve shaker machine. The sample is finally compressed in a small container with dimension of $19.5 \mathrm{~cm} \times 19.5 \mathrm{~cm} \times 11.5 \mathrm{~cm}$. Figure 2 shows a summary on process of sample preparation process. 


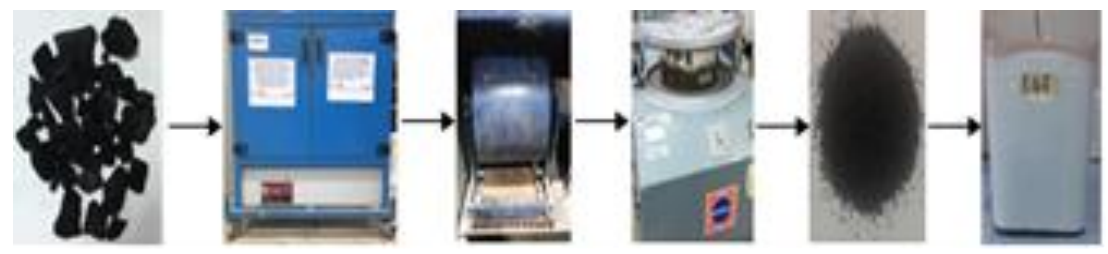

Figure 2. Sample testing preparation process

\subsection{Lightning Flashover Tests on Material}

Lightning flashover test is conducted to evaluate electrical performance under lightning condition. The impulse is generated by using $100 \mathrm{kV}$ single stage transformer and test arrangement as shown in Figure 3, capable of producing 1.2/50 us wave shapes impulse equivalent to natural lightning condition. High voltage rectifier convert $\mathrm{AC}$ source into DC which then charged using high voltage resistor and capacitor. Measuring resistor parallel with charging capacitor is used to measure the voltage and current. Spark gap is set to a distance of $2.0 \mathrm{~cm}$ spark gap which allows capacitor to be charge up to $60 \mathrm{kV}$.

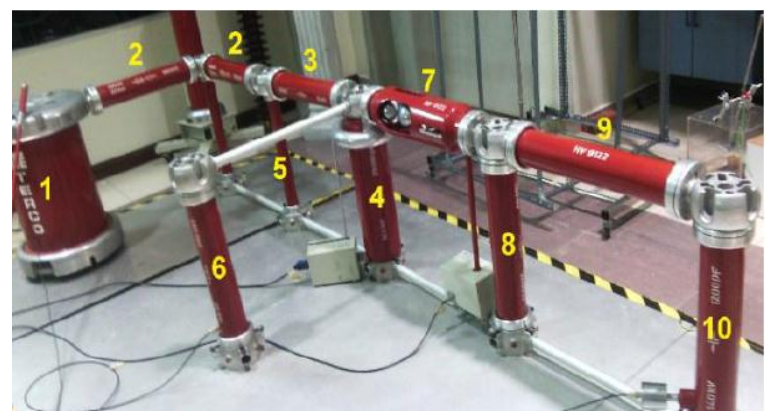

Figure 3. Single stage impulse generator consist of (1) HV Test Transformer, (2) Rectifier, (3) Charging Resistor, (4) Smoothing Capacitor, (5) Connecting Rod, (6) Measuring Resistor, (7) Sphere Gap,

(8) Wavetail Resistor, (9) Wavefront Resistor, (10) Load Capacitor

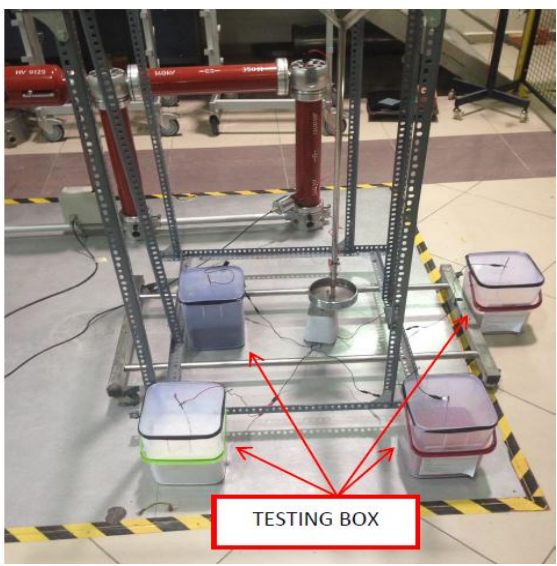

Figure 4. Material Placement

\subsection{Morphology Characterization of Material}

Physical and microstructure studies are examined using Field Emission Scanning Electron Microscope (FESEM). Each sample material is dispersed on double sided carbon adhesive tape that affixed on sample stubs and coated with conductive gold-palladium coating. The sample micrograph and structure is observed using FESEM and analysed in term of surface material and porosity. 


\subsection{Chemical Composition of Material}

The mineralogical analysis is performed using X-ray fluorescence (XRF) which could reveal chemical element in the sample material. Material in powder form is bind together with binder (licowax). It is used to strengthen the fine powder when molded into pallets form. Otherwise, the material could scatter from the pellet surface, which causes contamination of the spectrometers chamber. The material is finally compressed into small pallet using hydraulic bench press machine up to 5 bar pressure.

\section{RESULTS AND ANALYSIS}

\subsection{Lightning Flashover Tests}

Breakdown voltage is the condition changes after a certain voltage apply toward a material. It also indicates the maximum voltage for material capable to handle before collapse. The breakdown voltage for grounding is inversely condition from the insulator. Breakdown voltage for grounding is better if lower breakdown by means that it able to ground the low lightning strength for safety purpose. The results and general trend of breakdown voltage for bauxite and kaolin is shown in Figure 5.

As can be seen, the graph is plotting from $1^{\text {st }}$ September 2016 until end of January 2017 for every week. The breakdown voltage is recorded by using 'up and down' method. The graph trend is floating as the surrounding factor give an effect on breakdown voltage. It is clear that bauxite depicts a lower breakdown voltage level if compared to the kaolin.

In order to assess the life span of grounding material, the lightning flashover test is continued in the period interval of 1 month until the material fails. After five months, both materials still work well as grounding compound. The life span of bauxite and kaolin is found to be better than the similar research work [10] using brick clay which last only for three months.

The average breakdown voltage for 5 months is recorded in Table 1 . Bauxite as can be seen shows $0.58 \%$ different which about $0.8 \%$ lower than kaolin. Native erath is the reference for this two material. In addition, the measurement results are comparable to the native earth which makes it become a good and suitable candidate for ground compound. Further test to examine the ability of material for capturing lightning strike. The material connected together to air terminal and count the total strike receive each material at same period as shown in Figure 4. As proven, bauxite receives 32 strikes which is high compared to the kaolin, shown in Figure 6.

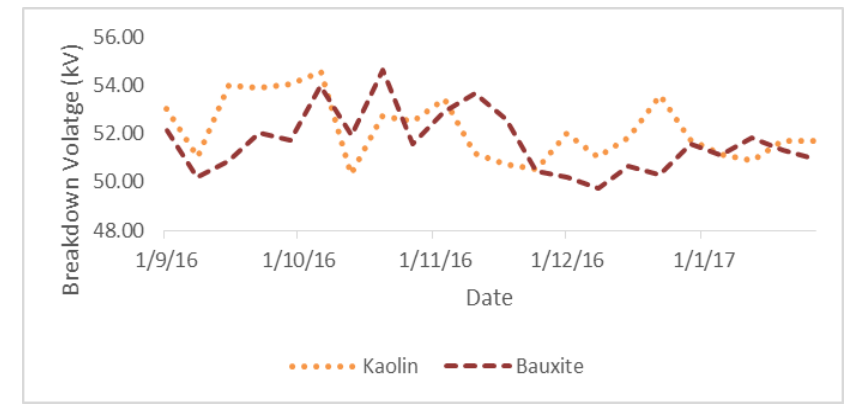

Figure 5. General trend of breakdown voltage

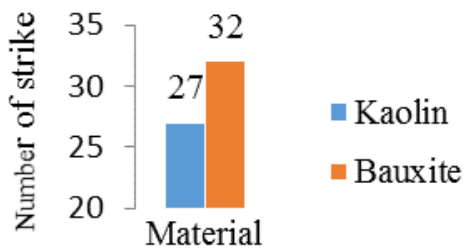

Figure 6. No of strike receives

Table 1. Material Breakdown Voltage and Percentage Different

\begin{tabular}{ccc}
\hline Material & $\begin{array}{c}\text { Breakdown } \\
\text { Voltage }(\mathrm{kV})\end{array}$ & $\begin{array}{c}\text { Percentage } \\
\text { different }(\%)\end{array}$ \\
\hline Kaolin & 51.34 & 0.66 \\
Bauxite & 51.30 & 0.58 \\
Native Earth & 51.00 & - \\
\hline
\end{tabular}

\subsection{Characterization of morphology grounding material}

The permeability and water holding capacity can be explained by looking at the amount, size and arragement of pores of the material. Permeability is the rate of water moves through the material while the water holding capacity is the ability of material to hold water. The porosity may affected by the soil texture, soil structure, compaction and organic matter. Figure 7(a) shows kaolin with small porosity can hold very large amount of water as it permeability is slow. It solid texture (in diameter) are small in particle size, feel 
sticky and hard to squeeze. Figure 7(b) is a bauxite with medium in pore size. It could hold medium amount of water as it permeability is moderate. This morpfology is the reason for its low resistivity.

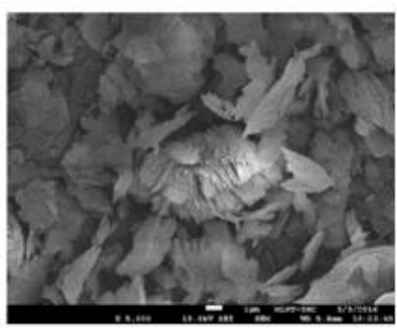

(a)

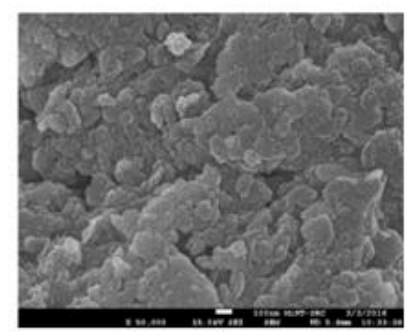

(b)

Figure 7. FESEM micrographs on structure of sample (a) Kaolin, (b) Bauxite

\subsection{Material Element Composition}

Recorded chemical changes before and after impulse is crucial part in analyzing the material element composition. Electrostatic is charge produce containing positive and negative charge character. The charge produces phenomena, clone with lightning behavior that produces positive and negative charge inside cloud before strike due to unbalance charge inside the cloud. During lightning strike, mostly positive charge inside cloud situated at the lower side of the cloud. As an electrical potential different concept, current flows from positive charge to negative charge. It occurs if the breakdown inside air achieves.

As it strikes because to balance back the unbalance charge, during that period mineral inside soil play importance role as capture as much positive ion. Capturing process called as cation exchange. Cation ion capacity is ability negative ion inside mineral soil to hold and absorb the positive ion in achieve stability [11]. This point explain the reason each of element inside the material decrease the percentage after conducting impulse or lightning (Table 2).

Electric conductivity is the ability of a material to conduct an electric current. It depends on salinity of material. Salt is the natural component in soil (material) and water. The ions responsible for salination are: Sodium, $\mathrm{Na}+$, Potassium, $\mathrm{K}+$, Calcium, $\mathrm{Ca} 2+$, Magnesium, $\mathrm{Mg} 2+$ and Chlorine, $\mathrm{Cl}-$. To conduct electricity, a substances needs charged particles free to move by heating it up or make the substances in aqueous and liquid state.

Mined kaolin contains silicon dioxide, $\mathrm{SiO} 2$ (quartz) as major contaminant which contribute 55.80\% of concentration and $24.10 \%$ concentration of aluminium oxide, $\mathrm{A} 12 \mathrm{O} 3$. SiO2 compounds are network solid as their bonding electrons are strong. It resists electron through it as it is a good insulator. Kaolin also build up by $24.10 \%$ concentration of $\mathrm{Al} 2 \mathrm{O} 3$. Metal $(\mathrm{Al})$ is react with non-metal $(\mathrm{O})$ to form ionic compound. Metal can loss the electrons and form metal cation while non-metal are electronegative and form anion. The cation and anion are combine together by electrostatic force of attraction known as ionic bond and this compound name as ionic compound. Kaolin have two ion that responsible for salination which is $\mathrm{K}$ and $\mathrm{Mg}$.

Bauxite are the main source of aluminium. It made up of $32.20 \%$ of $\mathrm{Al} 2 \mathrm{O} 3$ and $29.00 \%$ of iron oxide, $\mathrm{Fe} 2 \mathrm{O} 3$. $\mathrm{Fe} 2 \mathrm{O} 3$ changed the material colour from white to orange. It major concentration are in ionic compound. Al2O3 are high in thermal conductivity for ceramic material and insoluble in water. Bauxite have an ion that responsible for salination which is $\mathrm{K}$.

\begin{tabular}{|c|c|}
\hline Material & Percent Changes (\%) \\
\hline Kaolin & 6.39 \\
\hline Bauxite & 3.00 \\
\hline
\end{tabular}

\section{CONCLUSION}

The limitation faced in developing a small scale portable earthing system against the massiveness of Earth has now being addressed by the discovery of bauxite. Bauxite when it is use along with aspecial design earth electrode arrangement compacted and enclosed in enclosure can behaves like an earth terminal installed 
in the active Earth. Bauxite shows more lightning impulse capturing ability than its counterpart kaolin. Nevertheless, from chemical testing result, showed that bauxite soil is rich with a metal element which able to capture positive and negative ion produce from lightning phenomena By looking at bauxite morphology, it shows solid state is larger and occupies the space rather than void state. Thus, at high humidity it could absorb as well store more quantity of moisture. Because of that, bauxite is able to provide a low ground resistance to remote earth point when use is in the portable earthing system. The use of portable earthing system for high current and high voltage application will be the next stage of research.

\section{ACKNOWLEDGEMENTS}

The authors gratefully acknowledge Centre for Graduate Studies UTHM for partly sponsored and test facilities at the High Voltage Laboratory.

\section{REFERENCES}

[1] He, J., R. Zeng, and B. Zhang, Methodology and technology for power system grounding. 2012: John Wiley \& Sons.

[2] IEEE Guide for Generating Station Grounding. IEEE Std 665-1995, 1996: p. i.

[3] IEEE Guide for Safety in AC Substation Grounding. IEEE Std 80-2013 (Revision of IEEE Std 80-2000/ Incorporates IEEE Std 80-2013/Cor 1-2015), 2015: p. 1-226.

[4] Unde, M.G. and B.E. Kushare, "Impact of seasonal variation of soil resistivity on safety of substation grounding system. in Communication and Computing (ARTCom 2013), " Fifth International Conference on Advances in Recent Technologies in. 2013.

[5] Lees, F., "Loss prevention in the process industries: Hazard identification, assessment and control," 2012: Butterworth-Heinemann.

[6] Vijayaraghavan, G., M. Brown, and M. Barnes, "Practical grounding, bonding, shielding and surge protection", 2004: Butterworth-Heinemann.

[7] Hassan, W., M. Akmal, and M. Kamran, "Portable and compact grounding system. In Power Engineering Conference (UPEC)," 2013 48th International Universities'. 2013. M. P. Brown and K. Austin, Appl. Phys. Letters 85, 2503-2504 (2004).

[8] Unde, M.G. and B.E. Kushare, "Impact of seasonal variation of soil resistivity on safety of substation grounding system," in Communication and Computing (ARTCom 2013), Fifth International Conference on Advances in Recent Technologies in. 2013.

[9] Carter, M.R. and E.G. Gregorich, "Soil Sampling and Methods of Analysis," Second Edition. 2007: CRC Press.

[10] Mazlan, A.R., "Portable Ground Terminal for Grounding System Security Application," 2015, Universiti Tun Hussein Onn Malaysia.

[11] Young, A., Tropical Soils and Soil Survey. 1980: Cambridge University Press.

\section{BIOGRAPHIES OF AUTHORS}
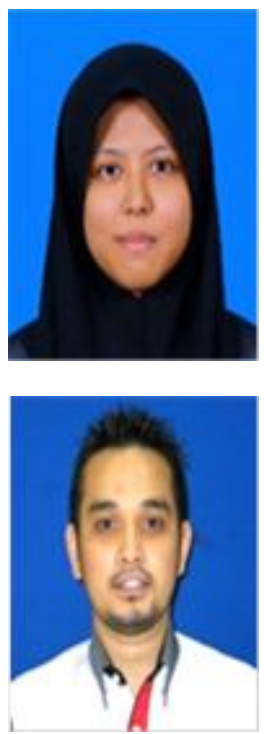

Nur Alyaa Mohd Hasni was born in 1991 and graduated with B.Eng (Electrical Engineering) from Universiti Tun Hussein Onn Malaysia (UTHM). Currently, she is doing her M.Eng (Electrical Engineering) in UTHM

R. Abd Rahman was born in Kedah, Malaysia in 1984. He received the M.Eng. degree in electrical and electronic engineering from Cardiff University, UK in 2008. After his graduation, he joined Universiti Tun Hussein Onn Malaysia (UTHM) as an academic staff and research fellow. In 2008, he came back to Cardiff as a PhD candidate within the High Voltage and Energy Systems group and received his phD in 2012. Currently, he is a lecturer at University of Tun Hussein Onn Malaysia (UTHM), Batu Pahat, Malaysia. 


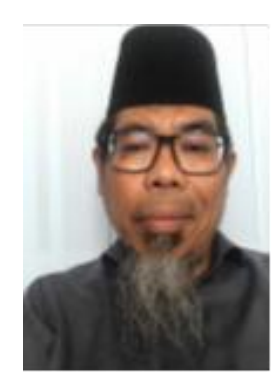

Hussein Ahmad was born in 1953 and graduated with BSc (Electrical and Electronic Engineering) and MSc (Electrical Power Engineering) from University of Strathclyde, Glasgow in 1977 and 1981 respectively. Subsequently received his $\mathrm{PhD}$ in high voltage engineering in 1986 from UMIST of University of Manchester. Currently he is a contract professor at the University of Tun Hussein Onn Malaysia (UTHM), Batu Pahat, Malaysia in the Research Center of Applied Electromagnetics in the Faculty of Electrical and Electronic Engineering, UTHM. He was the former Chairman and Head of Power Engineering Chapter, IEEE Malaysia Chapter. His last position in UTM before retirement in 2011 was Director of Institute of High Voltage and High Current (IVAT) and professor of the Faculty of Electrical Engineering, UTM,Skudai. His research interest is the area earthing, bonding, lightning protection, insulation performance and renewable energy using lightning. His is also the Director of Dynamic Electrical and Lightning Earthing Solution enterprise (DELES). 